\title{
The Effect of Microstructural Changes on Mechanical and Electrochemical Corrosion Properties of Duplex Stainless Steel Aged for Short Periods
}

\author{
David D. S. Silva ${ }^{1, *(\mathbb{D},}$, Lindolpho S. D. C. Lima ${ }^{2}$, Allan J. M. Araújo ${ }^{2}{ }^{(}$, Vinícius D. Silva ${ }^{3}$, \\ Rafael A. Raimundo ${ }^{1}$, Igor Z. Damasceno ${ }^{2}$, Thiago A. Simões ${ }^{4}$ and Rodinei M. Gomes ${ }^{1}$ \\ 1 Graduate Program in Mechanical Engineering, Federal University of Paraíba, João Pessoa 58051-900, Brazil; \\ rar@academico.ufpb.br (R.A.R.); rodinei@ct.ufpb.br (R.M.G.) \\ 2 Graduate Program in Materials Science and Engineering, Federal University of Rio Grande do Norte, \\ Natal 59078-970, Brazil; lindolpho.lima@bct.ect.ufrn.br (L.S.D.C.L.); allanmenezes@ufrn.edu.br (A.J.M.A.); \\ igorzumba@ufrn.edu.br (I.Z.D.) \\ 3 Graduate Program in Materials Science and Engineering, Federal University of Paraíba, \\ João Pessoa 58051-900, Brazil; vinicius.silva@ct.ufpb.br \\ 4 Center for Science and Technology in Energy and Sustainability, Federal University of Recôncavo da Bahia, \\ Feira de Santana 44042-280, Brazil; thiago.simoes@ufrb.edu.br \\ * Correspondence: david.silva@estudante.ufscar.br
}

Received: 1 November 2020; Accepted: 22 November 2020; Published: 3 December 2020

\begin{abstract}
This work reports the effects of microstructural changes due to the secondary phases, in particular sigma $(\sigma)$, on the mechanical properties and electrochemical behavior of thermally aged duplex stainless steel (DSS). Structural, morphological, mechanical, and electrochemical characterizations were performed. Sigma phase content increased with increasing aging treatment time. It had a net-like shape, as observed by electron backscatter diffractometry (EBSD). Its presence directly damaged mechanical properties. The corrosion assessment included electrochemical impedance spectroscopy (EIS) in $1 \mathrm{M} \mathrm{NaCl}$ solution at temperatures of 25,40 , and $65^{\circ} \mathrm{C}$. EIS results demonstrate that an increase in the $\sigma$ phase content decreased the corrosion resistance (21.1-0.8, $3.5-0.3$, and $3.1-0.2 \mathrm{k} \Omega \mathrm{cm}^{2}$ at 25,40 , and $60^{\circ} \mathrm{C}$, respectively).
\end{abstract}

Keywords: duplex stainless steel; sigma phase; electron backscatter diffractometry; mechanical properties; corrosion; electrochemical impedance spectroscopy

\section{Introduction}

Duplex stainless steels (DSSs) are ferritic-austenitic steels with ferrite $(\alpha-F e)$ and austenite $(\gamma-F e)$ volume fractions of about 1:1, providing an attractive combination of corrosion resistance and mechanical properties suitable for use in aggressive environments [1]. These properties, in combination with the effects of grain refinement obtained by the biphasic structure and the hardening by solid solution, has stimulated the use of DSSs in petrochemical, nuclear, cellulose industries, among others [2]. In addition, duplex alloys are often more resistant to corrosion and have superior mechanical properties to most common austenitic stainless steels, and they often overwhelm the performance of their austenitic counterparts. The ferritic structure confers high mechanical strength with high chloride-corrosion and stress-corrosion-cracking resistance, while the austenite renders high toughness with good resistance to hydrogen-induced stress-corrosion cracking [3,4].

The importance of controlling the microstructure of stainless steels in order to improve their material response is not only limited to duplex stainless steel. Escobar et al. [5] investigated the stabilization mechanism and austenite reversion during inter-critical tempering at $625{ }^{\circ} \mathrm{C}$ of a 
Ti-stabilized supermartensitic stainless steel (SMSS). The authors concluded that the austenite equilibrium phase fraction was reached after $2.5 \mathrm{~h}$ of isothermal reversion. Nonetheless, compositional homogenization was not reached within this soaking time. Escobar et al. [6] also studied the meta-equilibrium transition microstructure in a Ti-stabilized SMSS for maximum austenite stability and minimum hardness. The mechanism that explains the gradual increase in stable reverted austenite was the generation of a meta-equilibrium state, which resulted in a limit in both room-temperature austenite stabilization and high-temperature austenite reversion. However, maximizing reverted austenite and suppressing fresh martensite at room temperature did not lead to further reductions in hardness.

Despite all its advantages, DSS, when exposed to temperatures between 250 and $1000{ }^{\circ} \mathrm{C}$, generates the precipitation of undesired phases through casting, rolling, welding, forging, and aging processes that affect corrosion resistance and mechanical properties $[7,8]$. When the steel is exposed to temperatures between 250 and $550{ }^{\circ} \mathrm{C}$, the main reaction is related to the alpha-prime phase $\left(\alpha^{\prime}\right)$ precipitation by a spinodal decomposition mechanism [9]. Secondary phases (e.g., sigma $(\sigma)$, chi $(\chi)$, secondary austenite $\left(\gamma_{2}\right)$, as well as precipitates of chromium nitrides and carbides) are precipitated between 600 and $1000{ }^{\circ} \mathrm{C}$, and depending on the temperature to which the material is exposed, the sigma phase can appear after 5 min [10-18].

The surface oxide film on DSSs, called a passive film, can effectively hinder further interaction between the metal and its environment, particularly when the film is generated in aqueous environments [19]. The corrosion resistance of DSS depends strongly on the properties of the passive film and the alloying elements involved in surface oxidation [20]. Therefore, any factor that causes surface defects in passive film or chemical or physical heterogeneity, such as inclusions, second-phase particles, solute-segregated grain boundaries, flaws, mechanical damage, or dislocations, is considered a possible reason for a decrease in corrosion resistance [21].

The kinetics of $\sigma$ phase precipitation is controlled by the diffusion of $\mathrm{Cr}$ and Mo [22]. Regarding the $\gamma_{2}$ phase, $\mathrm{Cr}$ and Mo contents in $\alpha$-Fe decrease and Ni contents increase simultaneously after the precipitation of the $\sigma$ phase. The $\chi$ phase it presents a remarkably higher amount of Mo than any other phase present, and a similar Cr content to that of the $\alpha$-Fe phase [14,23]. During precipitation of these secondary phases, the elements responsible for DSS corrosion resistance are removed from the surroundings of these phases [7,24]. The precipitation of sigma phase enriched in $\mathrm{Cr}$ in the ferrite of DSS causes the segregation of the $\mathrm{Cr}$ concentration on the alloy surface. The higher the difference in $\mathrm{Cr}$ content between the $\sigma$ and $\gamma_{2}$ phases (a Cr-depleted zone), the worse the heterogeneity of the passive film and the poorer the resistance to pitting corrosion [21]. Therefore, the mechanical and corrosion properties of DSS are significantly modified by metallurgical variables $[25,26]$.

The effect of the sigma phase on mechanical properties deserves to be studied, since a small fraction of this phase affects ductility and toughness [27,28]. Recently, Silva et al. $[29,30]$ investigated the use of an electromechanical impedance (EMI) technique and low-field magnetic analysis (LFMA) in the monitoring of sigma phase embrittlement in DSS, in order to assess modifications in the microstructure of thermally degraded 2205 DSS at $800{ }^{\circ} \mathrm{C}$ for different time intervals. The authors confirmed that small $\sigma$ contents (about $6 \%$ ) promoted a considerable decrease of approximately $63 \%$ of toughness in DSS.

The influence of the sigma phase on the corrosion resistance of DSS has been reported as one of the major concerns of DSS welding [31-33]. Nonetheless, the characterization of DSS by directly linking microstructure (using electron backscatter diffractometry (EBSD)) to provide various structural and morphological data, and the relationship with electrochemical measurements, seems to be neglected in the literature.

In this regard, this work reports the use of EBSD along with electrochemical impedance spectroscopy (EIS) in order to understand the influence of secondary phases (mainly $\sigma$ phase precipitation) on the corrosion resistance of DSS. Furthermore, the effects of $\sigma$ phase on mechanical properties were studied by microhardness and tensile tests. For this, isothermal aging treatment at $800^{\circ} \mathrm{C}$ was performed for different durations $(15-180 \mathrm{~min})$. The temperature and periods 
of heat treatment were chosen in order to simulate processes such as welding and thermal aging, to which these materials may be exposed.

\section{Materials and Methods}

The specimens used in this investigation were commercial duplex stainless steel SAF2205. The chemical composition (in wt.\%) of the duplex stainless steel according to the ASTM A240/A240M-20 [34] was: C (0.025), Si (0.31), Mn (1.52), P (0.021), S (0.001), Cr (22.15), Mo (3.16), Ni (6.20), $\mathrm{Cu}(0.15), \mathrm{N}$ (0.176), and Fe (Bal.).

\subsection{Heat Treatment}

A solubilization heat treatment was carried out at $1155^{\circ} \mathrm{C}$ for $1 \mathrm{~h}$. Then, an isothermal aging treatment at $800^{\circ} \mathrm{C}$ was performed for $15,30,60$, and $180 \mathrm{~min}$. A specimen which was only solubilized (without aging treatment, $0 \mathrm{~min}$ ) was also used. The cooling was done by water quenching.

\subsection{Structural, Morphological, and Mechanical Characterization}

X-ray diffraction measurements were carried out within a scan range of $41.5-52.5^{\circ}$ (2-theta), with a step size of $0.02^{\circ}$ and $1 \mathrm{~s}$ per step by a diffractometer (SIEMENS D5000, Munich, Germany) equipped with $\mathrm{Cu}$ radiation $(\mathrm{K} \alpha, \lambda=1.5418 \AA)$. XRD patterns were compared to the card files: $\alpha$-Fe phase $\left(I C S D n^{\circ} 625865\right), \gamma$-Fe phase (ICSD n $\left.{ }^{\circ} 53803\right), \sigma$ phase (ICSD n $\left.{ }^{\circ} 102759\right)$, and $\chi$ phase (ICSD n ${ }^{\circ} 102758$ ).

Microstructural examination of the specimens was conducted using a light optical microscope (Olympus BX41M-LED, Tokyo, Japan). The specimens were polished by diamond paste $(6-0.25 \mu \mathrm{m})$ and then electrolytically etched by a $40 \% \mathrm{NaOH}$ electrolyte at $3 \mathrm{~V}$ etching potential for $30 \mathrm{~s}$, according to ASTM A923-14 [35].

Electron backscatter diffraction (EBSD) phase analysis was also employed. Metallographic polishing of specimens for EBSD measurements was carried out by standard preparation methods using diamond pastes with particle sizes down to $0.25 \mu \mathrm{m}$. In addition, residual stresses caused by the earlier stages of mechanical polishing were relieved by a final polishing step using a suspension of colloidal silica $(0.05 \mu \mathrm{m})$. Zeiss AURIGA field emission gun SEM (FEG-SEM, Zeiss, Oberkochen, Germany) equipped with a BRUKER e-FlashHR EBSD detector (Bruker, Billerica, MA, USA) was used. Step sizes were chosen between 47 and $230 \mathrm{~nm}$ and the voltage was $20 \mathrm{kV}$. ESPRIT 2.2 software (Bruker) was used to generate inverse pole figures (IPFs) and phase maps combined with the image quality (IQ). The EBSD area fractions of phases were obtained from the mean of three measurements.

The hardness test was conducted using a Vickers Micro Hardness Tester (Shimadzu HMV, Kyoto, Japan). The applied load and holding time were $200 \mathrm{~g}$ and $15 \mathrm{~s}$. The tensile test was performed by a Shimadzu AG-100KN electronic universal testing machine (Kyoto, Japan). Cylindrical specimens (Figure 1) were elongated at a constant cross-head speed of $2 \mathrm{~mm} / \mathrm{min}$ according to the ASTM-A370-20 [36] test method. The fractured surfaces of the specimens after testing were analyzed using the LEO 1430 scanning electron microscope (Carl Zeiss AG, Jena, Germany).

(a)

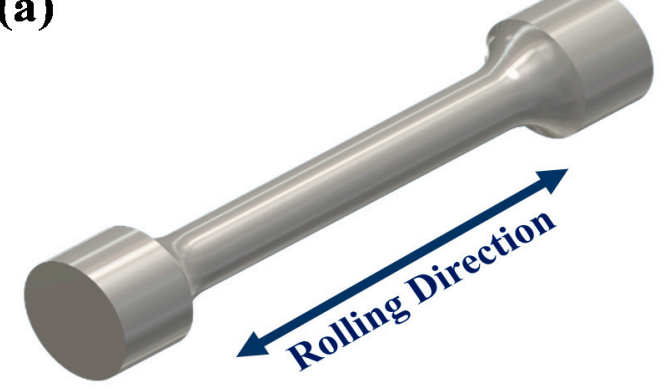

(b)

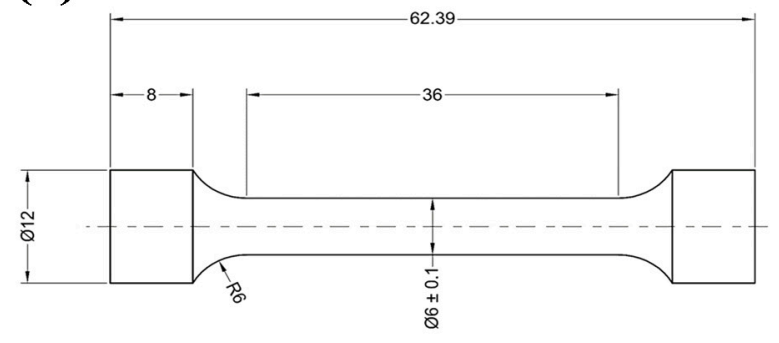

Figure 1. (a) Schematic illustration of the tensile specimens and (b) dimensions in $\mathrm{mm}$ of an ASTM-A370-20 (2020) test specimen. 


\subsection{Electrochemical Corrosion Characterization}

EIS studies were performed using a PGSTAT204-FRA32M (Metrohm Autolab, Utrecht, The Netherlands). A three-electrode cell (volume $100 \mathrm{~mL}$ ) in naturally aerated conditions was used. DSS specimens with different heat treatments were used as a working electrode (leaving an exposed area for corrosion test of $0.80 \mathrm{~cm}^{2}$ ) and further sanded on abrasive papers with grain size ranging from 220 to $600 \mu \mathrm{m} / \mathrm{mm}^{2}$. Platinum wire and $\mathrm{Ag} / \mathrm{AgCl}(3 \mathrm{M} \mathrm{KCl})$ were used as counter and reference electrodes, respectively. Before starting the EIS tests, the specimens were passivated using an aqueous solution containing $20 \% \mathrm{HNO}_{3}$ at $40{ }^{\circ} \mathrm{C}$ for $20 \mathrm{~min}$.

All EIS experiments were performed in a $1 \mathrm{M} \mathrm{NaCl}$ solution at temperatures of 25,40 , and $65^{\circ} \mathrm{C}$ (controlled using a hot plate and thermometer). Before testing, the working electrodes were immersed in the test solution for $30 \mathrm{~min}$ until steady-state open-circuit potential (OCP) was reached. EIS was carried out at the OCP to electrochemically characterize the specimen/electrolyte interface. EIS measurements were carried out in the frequency range $1 \mathrm{MHz}-1 \mathrm{~Hz}$ using a voltage amplitude of $5 \mathrm{mV}$.

Roughness measurements by optical profilometry were conducted using a CCI MP Taylor Hobson ${ }^{\circledR}$ profilometer (Taylor Hobson, Leicester, UK). The results were analyzed using TalyMap ${ }^{\circledR} 5$ software (Taylor Hobson). Specimens were magnified $(\times 50)$ with a resolution of $1024 \times 1024$ pixels. The 3D topography of the surface was acquired by combining several measurements.

\section{Results and Discussion}

\subsection{Structural, Morphological, and Mechanical Characterization}

XRD patterns of all the specimens are shown in Figure 2a. The solubilized specimen had no intermetallic phases, and only characteristic peaks of $\alpha$-Fe and $\gamma$-Fe phases were identified. However, $\chi$ and $\sigma$ phases were also identified for the aged specimens. Note that the $\chi$ phase diffraction peak (332) is coincident with the $\sigma$ phase peak (222). The intensity of $\sigma$ phase peaks increased with increased aging time, accompanied by a reduction in the intensity of the $\alpha$-Fe phase peak (011).

(a)

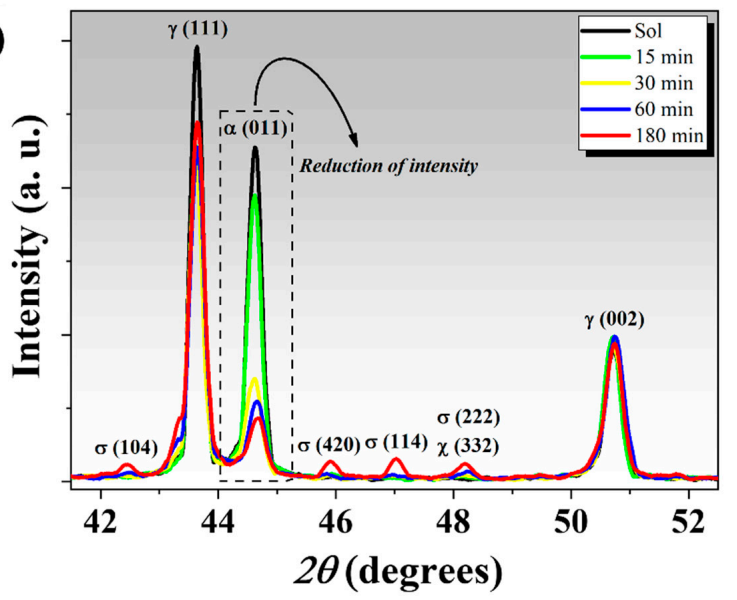

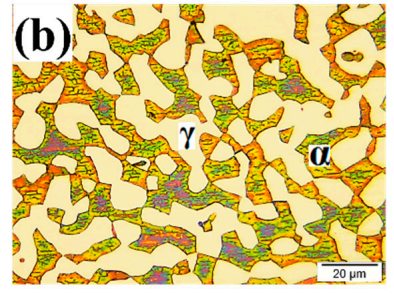

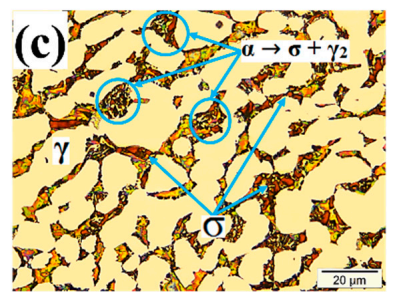

(d) Solubilization

With prolonged aging time

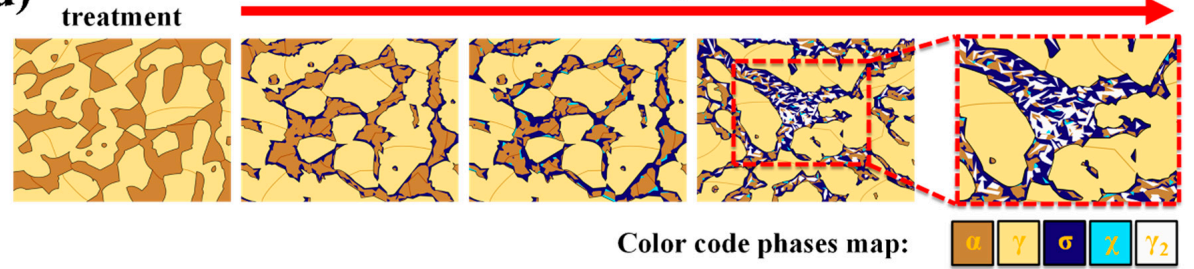

Figure 2. (a) XRD patterns, (b,c) OM of the specimens (0 and $180 \mathrm{~min}$ of aging, respectively), and (d) a schematic illustration of the microstructural evolution of DSS with prolonged aging time. 
Figure $2 b, c$ displays the microstructures for the solubilized specimen, and for the one aged for $180 \mathrm{~min}$. The solubilized specimen only contained $\alpha$-Fe and $\gamma$-Fe phases, while formation of the $\sigma$ phase could be seen after aging. The precipitation of the $\sigma$ phase led to the formation of $\gamma_{2}$ in a process defined as eutectoid decomposition $\left(\alpha \rightarrow \sigma+\gamma_{2}\right)$; as seen in Figure 2c. These results are in agreement with previously studies $[29,30]$.

These optical microscopies (OM) show that the secondary phases grew at the expense of the $\alpha$-Fe phase. However, these results do not provide a good contrast for distinguishing between the various secondary phases, mainly the $\sigma, \chi$, and $\gamma_{2}$ phases. In order to clarify the precipitation behavior and phase transformation of DSS, a schematic illustration is shown in Figure $2 \mathrm{~d}$.

Considering that it is almost impossible to differentiate sigma and chi phases using the XRD and OM techniques, especially in the earlier stages of aging, electron backscatter diffractometry (EBSD) analysis was performed. Figure 3 shows the EBSD phase maps and inverse pole figure (IPF) maps. The contrast on these maps provides useful visualization of grain boundaries, permitting the alignment of different images. These results illustrating the distribution and morphology of phases which precipitating at different aging times. The maps clearly show the distribution of the different phases in duplex stainless steel.
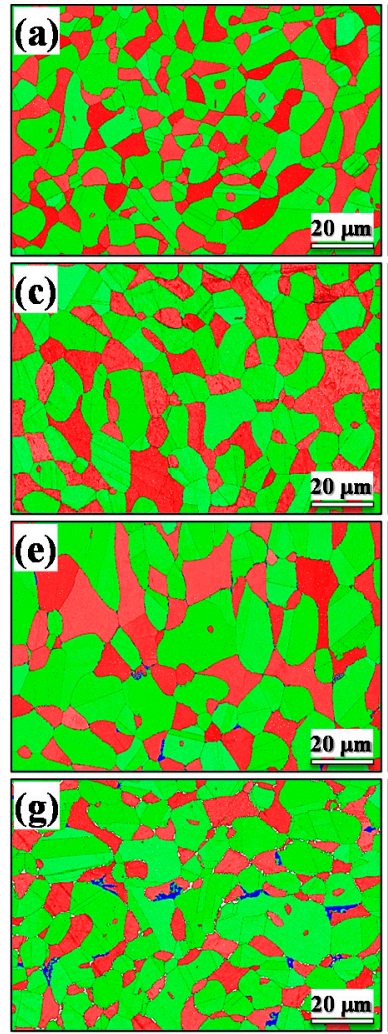
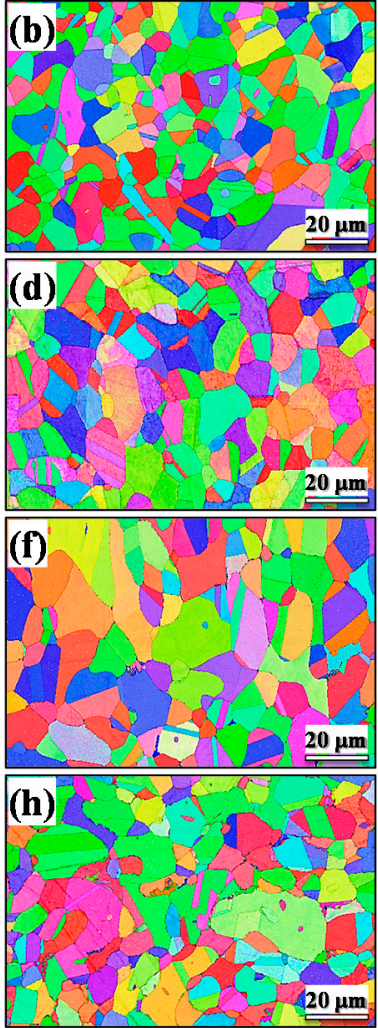
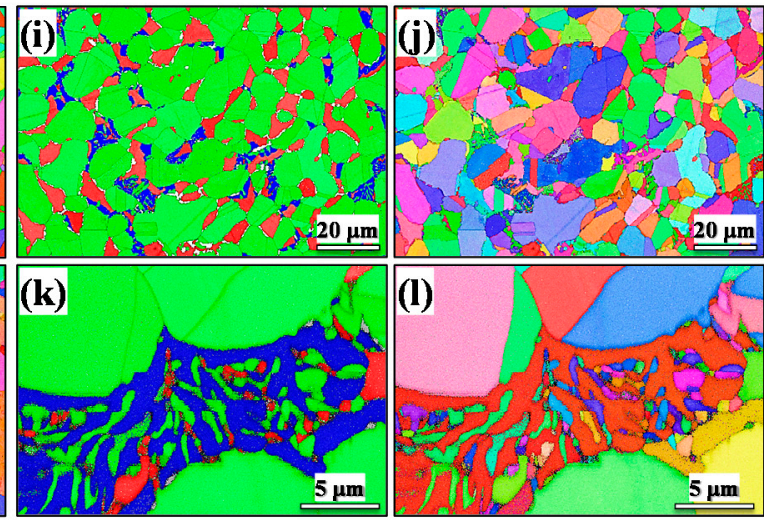

(m)

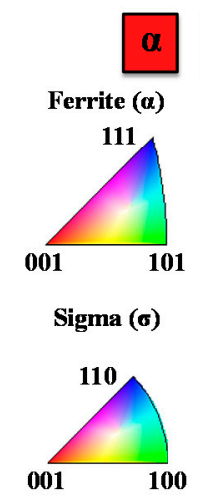

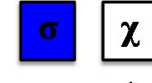

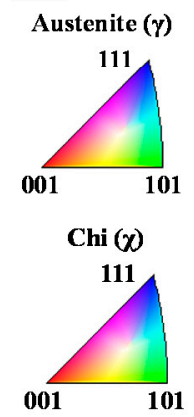

Figure 3. Electron backscatter diffractometry (EBSD) phase map of the specimens in the following conditions: (a) solubilized and aged for (c) $15 \mathrm{~min}$, (e) $30 \mathrm{~min}$, (g) $60 \mathrm{~min}$, and (i,k) $180 \mathrm{~min}$. Inverse pole figure (IPF) orientation maps of the specimens in the following conditions: (b) solubilized and aged for (d) $15 \mathrm{~min}$, (f) $30 \mathrm{~min}$, (h) $60 \mathrm{~min},(\mathbf{j}, \mathbf{1})$ and $180 \mathrm{~min}$; (m) color code map for IPF [001]. Note that the aged specimen for $180 \mathrm{~min}$ has two images (medium and high magnification).

Note that the initial microstructure (Figure 3a) consisted only of $\alpha$-Fe and $\gamma$-Fe phases. However, the microstructures of the aged specimens in Figure 3c,e,g,i (15, 30, 60, and 180 min aging, respectively) showed a fraction of secondary phases $\left(\sigma, \chi\right.$, and $\left.\gamma_{2}\right)$ which formed during the aging treatment [27]. These results are in agreement with the XRD and OM results. A high-magnification EBSD map (Figure 3k) allowed us to observe the microstructure of specimens aged for $180 \mathrm{~min}$. $\gamma_{2}$ formed 
together with other secondary phases associated with eutectoid $\sigma$ phase formation in the ferrite, resulting in elongated net-like shapes. $\chi$ precipitates were seen with an elongated shape. $\sigma$ phase had preferential growth along the phase boundaries with an allotriomorphic morphology towards ferrite grain interiors [37]. Based on the IPF maps, no specific texture was observed, and these phases were found to be randomly distributed. Similar behavior was previously reported [38].

Quantitative analysis of phases measured by EBSD is shown in Table 1. For each specimen, three EBSD images were obtained, the average of three measurements was reported, and the errors were based on the standard error of the mean. With the measurement methodology applied, the relative error of the area fraction evaluation of phases did not exceed $2.5 \%$. The area fractions of the secondary phases increased with the increase of the heat treatment time. The $\sigma$ phase increased from $0.4 \%$ to $6.8 \%$ and the $\chi$ phase increased from $1.2 \%$ to $2.3 \%$, resulting in a decrease in the $\alpha$-Fe phase from $37.5 \%$ to $17.2 \%$ with increasing aging time. The overall fraction of the $\gamma_{2}$ phase formed was about $11.2 \%$, which was determined by the difference between the content of the specimen aged for $180 \mathrm{~min}$ and the solubilized specimen. These results are following those previously reported $[37,39]$.

Table 1. Normalized area fraction of phases measured by EBSD.

\begin{tabular}{cccccc}
\hline Phase & Solubilized & $\mathbf{1 5} \mathbf{~} \mathbf{\text { in }}$ & $\mathbf{3 0} \mathbf{~} \mathbf{m i n}$ & $\mathbf{6 0} \mathbf{~} \mathbf{m i n}$ & $\mathbf{1 8 0} \mathbf{~}$ in \\
\hline$\% \alpha$ & $37.5 \pm 0.7$ & $35.6 \pm 2.2$ & $31.4 \pm 1.3$ & $27.8 \pm 0.6$ & $17.2 \pm 0.6$ \\
$\% \gamma$ & $62.5 \pm 0.7$ & $64.0^{(*)} \pm 2.2$ & $67.7^{(*)} \pm 1.1$ & $69.3^{(*)} \pm 0.9$ & $73.7^{(*)} \pm 0.8$ \\
$\% \sigma$ & $\mathrm{n} / \mathrm{a}$ & $0.4 \pm 0.1$ & $0.9 \pm 0.2$ & $1.7 \pm 0.1$ & $6.8 \pm 0.3$ \\
$\% \chi$ & $\mathrm{n} / \mathrm{a}$ & $\mathrm{n} / \mathrm{a}$ & $\mathrm{n} / \mathrm{a}$ & $1.2 \pm 0.1$ & $2.3 \pm 0.3$ \\
\hline
\end{tabular}

n/a: not available; $\left({ }^{*}\right)$ : Secondary austenite included.

The influence of the $\sigma$ phase on the mechanical properties of the DSS was examined by conducting tensile and microhardness tests. Figure 4 shows the typical stress versus strain curves for the UNS S31803 DSS specimens determined from uniaxial tensile test data. A summary of the results of the tensile test and the microhardness test are shown in Table 2 . The microhardness $\left(\mathrm{HV}_{0.2}\right)$ value increased by around $19 \%$, resulting in a reduction of about $35 \%$ in strain $(\varepsilon)$, showing clear signs of sigma phase embrittlement. The increase in $\sigma$ content led to an increase in the yield strength $\left(\sigma_{y}\right)$, with values ranging from 507 to $561 \mathrm{MPa}$. However, notice that the ultimate tensile strength $\left(\sigma_{u}\right)$ was almost the same for all the specimens with a variation less than $5.5 \%$. In general, the reduction in cross-sectional area (\%RA) is a characteristic which describes the ductility together with the tensile test data. The solubilized specimen had a large \%RA, about $57 \%$, while the specimen aged for 180 min exhibited a \%RA below $15 \%$, showing a brittle behavior. This is due to the increased amount of the $\sigma$ phase $[27,29]$.

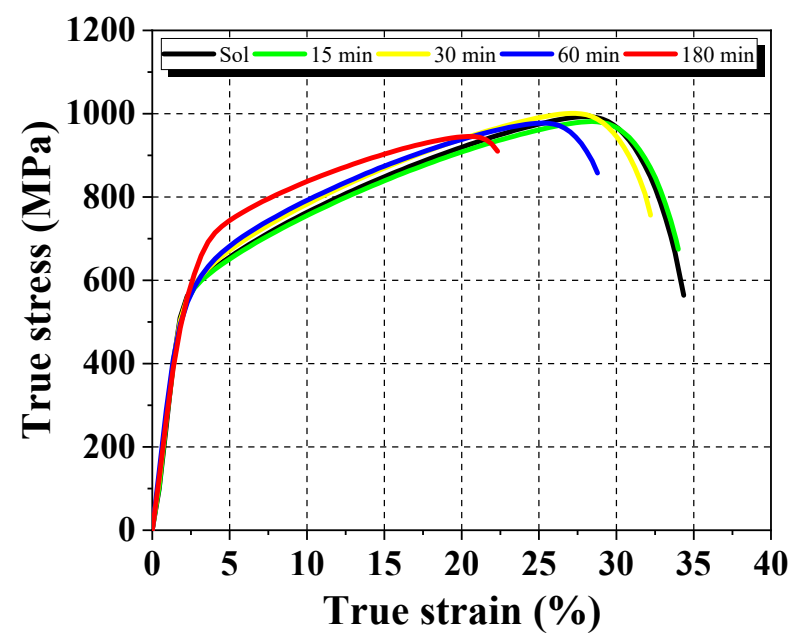

Figure 4. True stress versus true strain behavior as a function of aging time at $800{ }^{\circ} \mathrm{C}$. 
Table 2. Summary of mechanical properties.

\begin{tabular}{cccccc}
\hline Specimen & $\left.\mathbf{( H V}_{\mathbf{0 . 2}}\right)$ & $\boldsymbol{\sigma}_{\boldsymbol{u}} \mathbf{( M P a )}$ & $\boldsymbol{\sigma}_{\boldsymbol{y}} \mathbf{( M P a )}$ & $\boldsymbol{\varepsilon} \mathbf{( \% )}$ & $\mathbf{( \% R A )}$ \\
\hline Solubilized & $257 \pm 0.5$ & $993 \pm 2.8$ & $507 \pm 1.5$ & $34 \pm 1.2$ & $57 \pm 1.3$ \\
$15 \mathrm{~min}$ & $266 \pm 3.1$ & $981 \pm 3.1$ & $507 \pm 2.9$ & $34 \pm 1.7$ & $49 \pm 0.7$ \\
$30 \mathrm{~min}$ & $271 \pm 2.6$ & $1001 \pm 2.5$ & $558 \pm 1.3$ & $32 \pm 0.8$ & $37 \pm 1.2$ \\
$60 \mathrm{~min}$ & $287 \pm 0.7$ & $977 \pm 2.7$ & $561 \pm 2.2$ & $29 \pm 1.5$ & $25 \pm 0.6$ \\
$180 \mathrm{~min}$ & $305 \pm 2.7$ & $946 \pm 3.3$ & $561 \pm 1.6$ & $22 \pm 1.4$ & $15 \pm 0.7$ \\
\hline
\end{tabular}

Figure 5 shows SEM images of the surfaces of tested materials. Figure 5 a shows the fracture surfaces of the solubilized specimen with a characteristic ductile fracture mechanism, wherein a large number of deep dimples and voids can be observed. Figure $5 b$ shows the fracture morphology of the specimen aged for $15 \mathrm{~min}$. The ductile fracture mode is evident again, with significant heterogeneous-size dimples. The specimen aged for 30 min (Figure 5c) shows the mixed mode of ductile and brittle fracture morphology. Figure 5d,e shows the fracture morphology of the specimens aged for 60 and $180 \mathrm{~min}$, respectively. More extensive cracking was observed with significantly less necking and fewer dimples-all indicating embrittlement. Cleavage fracture areas were observed, which indicated strain heterogeneity in the microstructure. The presence of the $\sigma$ phase can cause localized tearing that forms cracks. These results are in accordance with those previously reported [27-29,40].
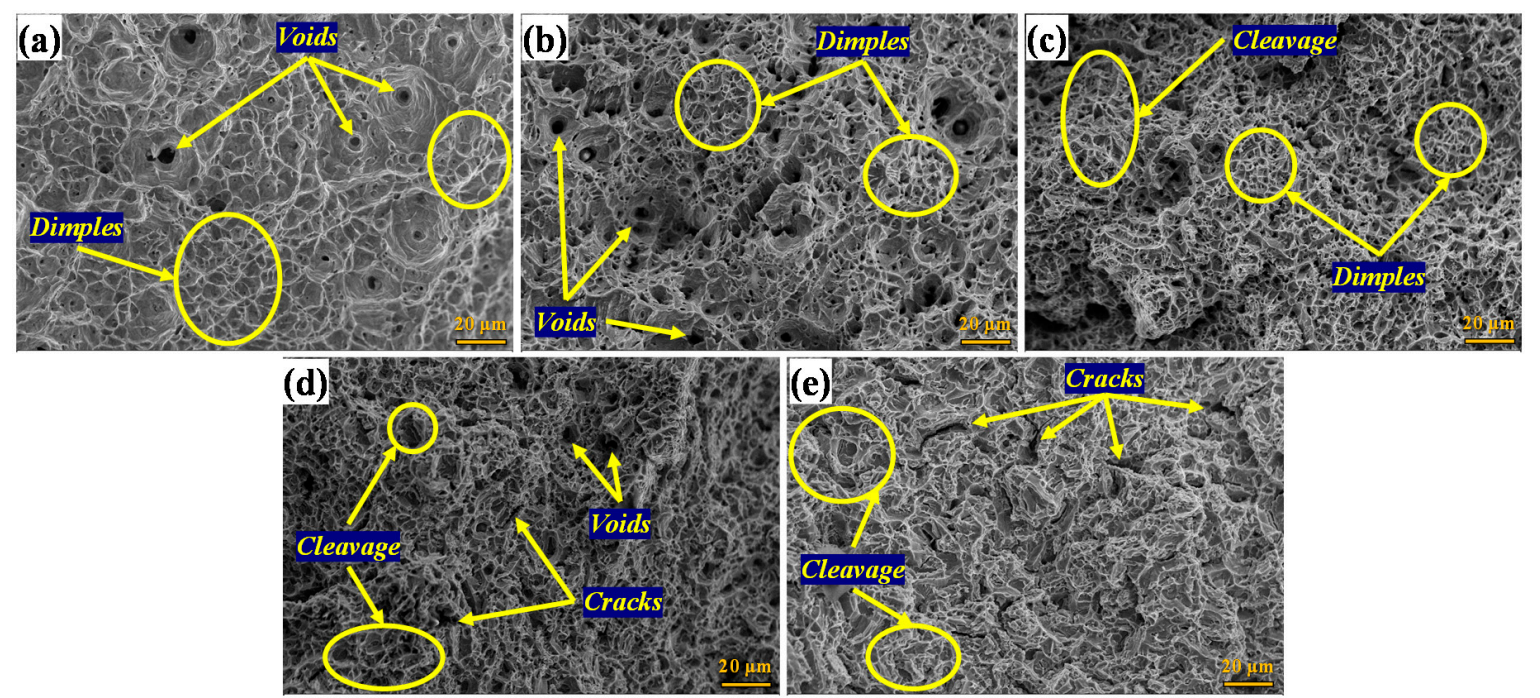

Figure 5. (a-e) SEM of fracture surfaces of the specimens (0-180 $\mathrm{min}$, respectively).

\subsection{Electrochemical Corrosion Tests}

The surface roughness of a metal has a major influence on corrosion resistance. An increase in the surface roughness of stainless steels results in an increase in pitting susceptibility and in the general corrosion rate [41]. For the case of DSS, which form a passive layer, a decrease in surface roughness increases corrosion resistance [42]. Therefore, taking into account that the initial roughness can influence the corrosion resistance of the material, roughness measurements are necessary to prove that all specimens were subjected to the corrosion test with similar surface roughness, thus ensuring that only the precipitation of secondary phases influences the corrosion resistance, as well as the temperature of the electrochemical test. 2D and 3D surface roughness profile results (Figure S1) and further details on this characterization can be found in the Supplementary Material.

EIS tests were used to investigate the electrode-electrolyte interface (Figure 6a-f). Electrochemical impedance spectra are shown in Figure $6 \mathrm{a}, \mathrm{c}, \mathrm{e}$. The spectra were fitted using a Randles circuit, $\left(R_{S}\left(R_{P} C P E\right)\right)$, as inserted in Figure 6a,c,e. Nyquist results show that there was a decrease in the diameter of the depressed impedance arc, regardless of the temperature. These changes 
are also clear in the Bode phase plot where by increasing the temperature and the amount of sigma phase, the impedance value $(|\mathrm{Z}|$ ) (Figure $6 \mathrm{~b}, \mathrm{~d}, \mathrm{f}$ ) at the frequency of $1 \mathrm{~Hz}$ decreased from 3.0 to $0.8 \mathrm{k} \Omega$ $\mathrm{cm}^{2}\left(25^{\circ} \mathrm{C}\right), 1.5$ to $0.3 \mathrm{k} \Omega \mathrm{cm}^{2}\left(40^{\circ} \mathrm{C}\right)$, and 1.25 to $0.2 \mathrm{k} \Omega \mathrm{cm}^{2}\left(65^{\circ} \mathrm{C}\right)$. This behavior can be associated with a decrease in the impedance module, indicating a decrease in corrosion resistance. In general, an increase in the impedance arc indicates a decrease in the corrosion rate of the electrolyte-electrode system [21]. The impedance arc radius decreased with increasing thermal aging time (charge transfers through the passive film with ease). In the high frequencies (close to $10 \mathrm{kHz}$ ), the electrolyte impedance values decreased for all specimens due to the temperature effect, characterizing a system that consists of only the resistance of electrolytes and decreased impedance of passive films [43].

(a)

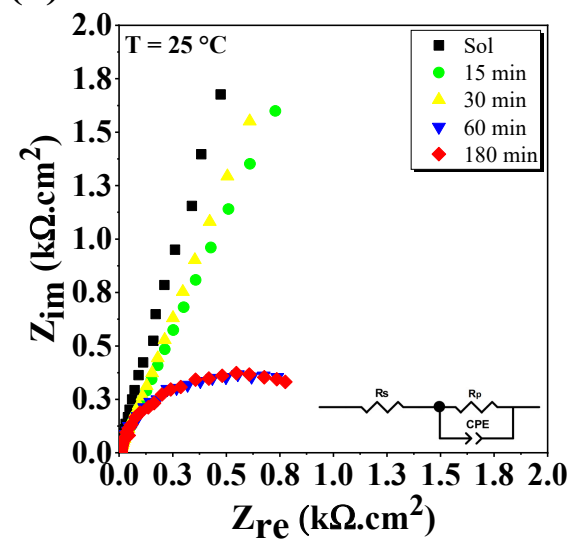

(c)

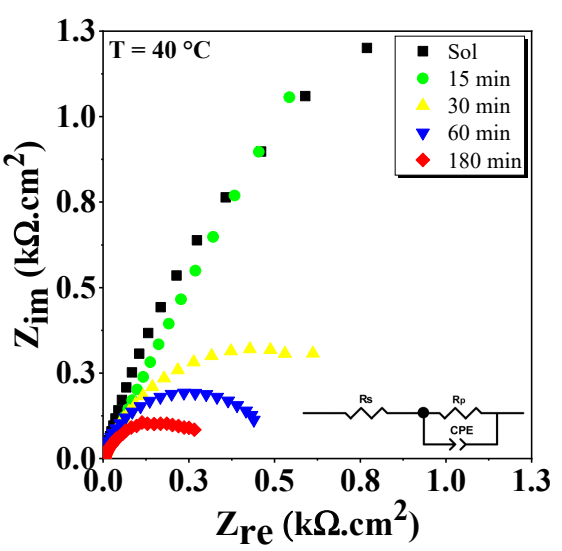

(e)

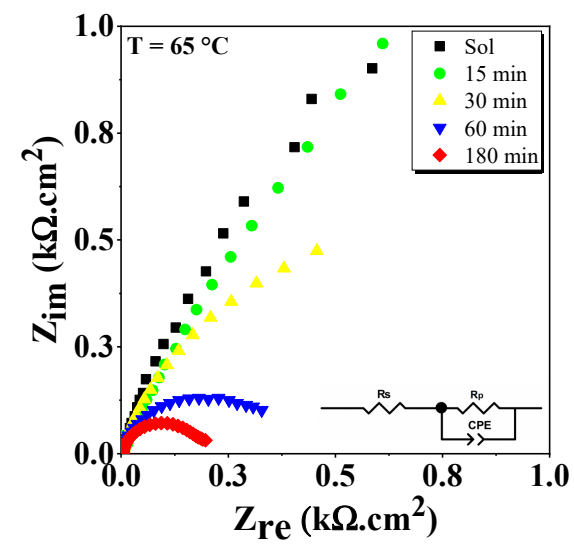

(b)

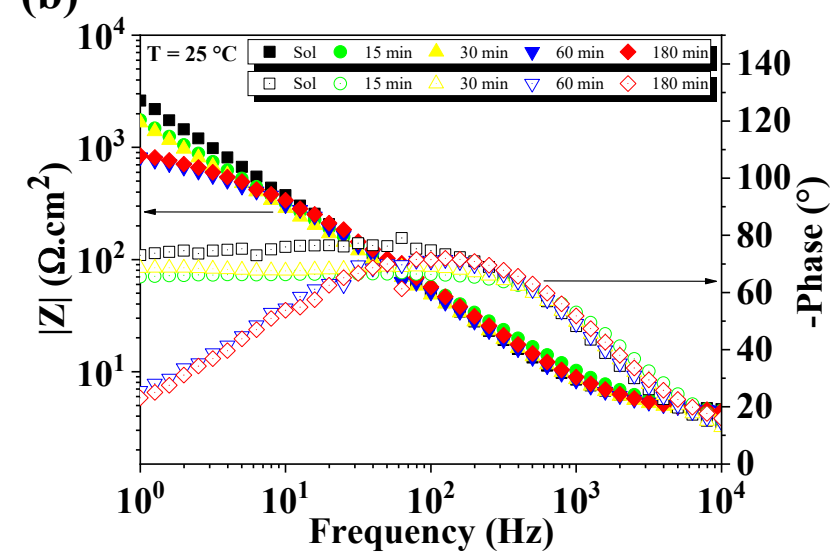

(d)

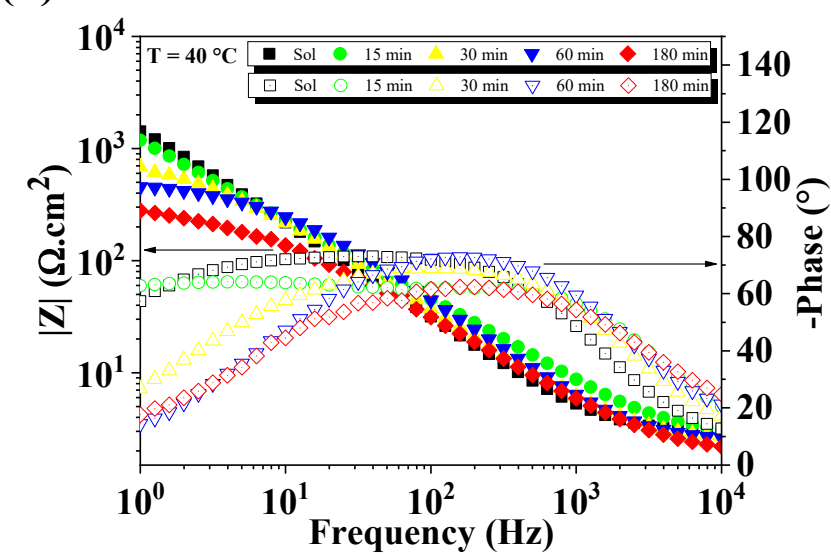

(f)

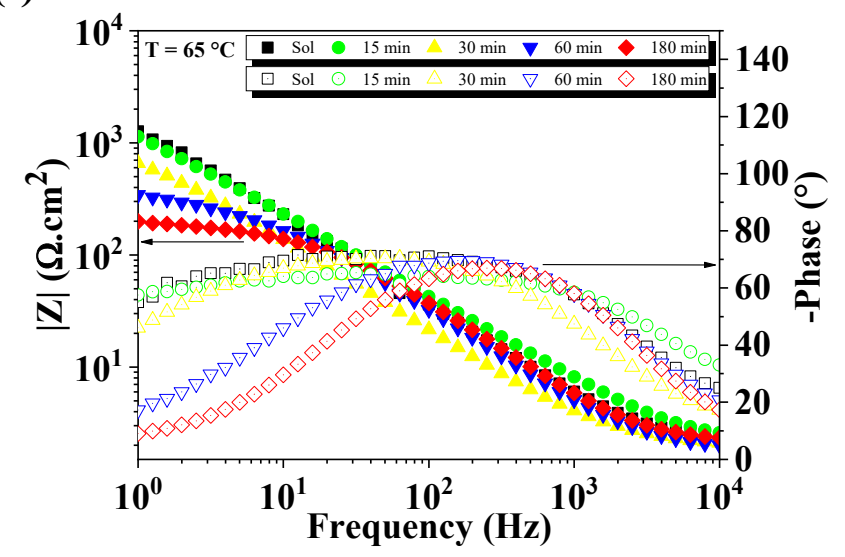

Figure 6. EIS results at: $(\mathbf{a}, \mathbf{b}) 25^{\circ} \mathrm{C},(\mathbf{c}, \mathbf{d}) 40{ }^{\circ} \mathrm{C}$, and $(\mathbf{e}, \mathbf{f}) 65^{\circ} \mathrm{C}$. 
Modeling the impedance of more complex real systems requires the use of equivalent circuits with constant phase elements $(C P E s)$. The $C P E$ has a fixed phase-shift angle and its impedance is described by Equation (1):

$$
Z_{C P E}=P^{-1}(j \omega)^{-n}
$$

where $Z_{C P E}$ is the $C P E^{\prime}$ s impedance, $\omega$ is the angular frequency, $j$ is the imaginary unit, $P$ is the proportionality factor, $n$ is the phase shift, $j=(-1)^{1 / 2}$, and $\omega=2 \pi f$, where $f$ is the frequency $(\mathrm{Hz})$. The factor $n$ depends on the surface morphology and is the deviation parameter $(-1 \leq n \leq 1)$, where -1 is characteristic for an inductance, 1 corresponds to a capacitor, and 0 corresponds to a resistor [44].

For a circuit including a $C P E$, the double-layer capacitance $\left(C_{\text {Pass }}\right)$ can be calculated according to Equation (2) [45]:

$$
C_{\text {Pass }}=P^{1 / n} R_{c t}^{(1-n) / n}
$$

where $R_{c t}$ represents the charge transfer resistance. In the proposed equivalent circuit, $R_{S}$ stands for the resistance of the electrolyte between the working electrode and the reference electrode, while the element $R_{p}$ is the polarization resistance. CPEs are often used to replace the capacitance, giving a more accurate fit to the impedance data. It is related to the capacity of the material surface area of complex surface roughness, inhomogeneous reaction rates on a surface, and non-uniform current distribution [46]. All values obtained for $R_{s}, R_{p}$, and $C_{\text {Pass }}$ are listed in Table 3.

\begin{tabular}{|c|c|c|c|c|}
\hline \multicolumn{5}{|c|}{ Test Results at $25^{\circ} \mathrm{C}$} \\
\hline \multirow{2}{*}{ Specimen } & \multicolumn{4}{|c|}{ CPE Parameters } \\
\hline & $R_{s}\left(\Omega \mathrm{cm}^{2}\right)$ & $C_{\text {Pass }}\left(\mu \mathrm{F} \mathrm{cm}^{-2}\right)$ & $n$ & $R_{p}\left(\mathrm{k} \Omega \mathrm{cm}^{2}\right)$ \\
\hline Solubilized & 3.14 & 4.31 & 0.85 & 21.11 \\
\hline $15 \mathrm{~min}$ & 2.35 & 6.84 & 0.75 & 12.88 \\
\hline $30 \mathrm{~min}$ & 1.92 & 7.91 & 0.77 & 9.74 \\
\hline $60 \mathrm{~min}$ & 1.06 & 8.77 & 0.78 & 0.84 \\
\hline $180 \mathrm{~min}$ & 0.98 & 10.84 & 0.77 & 0.84 \\
\hline \multicolumn{5}{|c|}{ Test Results at $40^{\circ} \mathrm{C}$} \\
\hline \multirow{2}{*}{ Specimen } & \multicolumn{4}{|c|}{ CPE Parameters } \\
\hline & $R_{s}\left(\Omega \mathrm{cm}^{2}\right)$ & $C_{\text {Pass }}\left(\mu \mathrm{F} \mathrm{cm}^{-2}\right)$ & $n$ & $R_{p}\left(\mathrm{k} \Omega \mathrm{cm}^{2}\right)$ \\
\hline Solubilized & 4.36 & 8.24 & 0.86 & 3.50 \\
\hline $15 \mathrm{~min}$ & 2.86 & 12.84 & 0.73 & 3.49 \\
\hline $30 \mathrm{~min}$ & 0.68 & 11.21 & 0.78 & 0.73 \\
\hline $60 \mathrm{~min}$ & 0.54 & 12.23 & 0.82 & 0.40 \\
\hline $180 \mathrm{~min}$ & 0.48 & 20.75 & 0.72 & 0.26 \\
\hline \multicolumn{5}{|c|}{ Test Results at $65^{\circ} \mathrm{C}$} \\
\hline \multirow{2}{*}{ Specimen } & \multicolumn{4}{|c|}{$C P E$ Parameters } \\
\hline & $R_{s}\left(\Omega \mathrm{cm}^{2}\right)$ & $C_{\text {Pass }}\left(\mu \mathrm{F} \mathrm{cm}^{-2}\right)$ & $n$ & $R_{p}\left(\mathrm{k} \Omega \mathrm{cm}^{2}\right)$ \\
\hline Solubilized & 2.37 & 10.97 & 0.81 & 3.08 \\
\hline $15 \mathrm{~min}$ & 1.84 & 12.71 & 0.71 & 2.27 \\
\hline $30 \mathrm{~min}$ & 0.53 & 16.75 & 0.79 & 1.07 \\
\hline $60 \mathrm{~min}$ & 0.41 & 17.45 & 0.77 & 0.32 \\
\hline $180 \mathrm{~min}$ & 0.31 & 41.78 & 0.78 & 0.16 \\
\hline
\end{tabular}

Table 3. EIS Fitting parameters.

Table 3 shows that $R_{p}$ decreased with increasing amount of sigma phase, and its value was affected by temperature. The greater the $R_{p}$, the greater the resistance of the material to corrosion [47]. Moreover, the increase of the $C_{\text {Pass }}$ value may be related to a worse stability of the passive film on the electrode surface $[43,48]$. 
The decrease in corrosion resistance is directly attributed to the formation of the sigma phase, as reported in previous work [49-51]. However, the corrosion performance of microstructures containing a secondary austenite with a decrease in corrosion resistance has been reported in some studies [52]. Therefore, for a more complete study of the corrosion resistance of duplex stainless steel, the effects of each secondary phases must be taken into account [37].

This work stands out from other studies due to the possibility of studying crystallographic changes by means of EBSD and, therefore, understanding the effects on the mechanical properties and electrochemical corrosion behavior of duplex stainless steel.

\section{Conclusions}

In summary, the structural and morphological characterization proved the presence of the sigma phase with net-like shapes, and its precipitation occurred regularly and by eutectoid decomposition of ferrite, as evidenced by EBSD. Sigma phase content increased as aging treatment time increased, and it was proved that short-term aging can significantly deteriorate material ductility. EIS indicated that the corrosion resistance of DSS decreased with increases in both the sigma phase content and the measurement temperature. Therefore, EBSD analysis combined with EIS tests was found to be a successful approach to assess the decrease in corrosion resistance of DSS with secondary phases.

Supplementary Materials: The following are available online at http://www.mdpi.com/1996-1944/13/23/5511/s1, Figure S1: 2D and 3D surface profiles of the specimens (0-180 $\mathrm{min}$, respectively).

Author Contributions: Conceptualization, D.D.S.S., T.A.S., and R.M.G.; methodology, D.D.S.S.; software, D.D.S.S.; validation, D.D.S.S., T.A.S., and R.M.G.; formal analysis, D.D.S.S., L.S.D.C.L., A.J.M.A., V.D.S., R.A.R., I.Z.D., and T.A.S.; investigation, D.D.S.S.; writing-original draft preparation, D.D.S.S.; writing—review and editing, D.D.S.S., L.S.D.C.L., A.J.M.A., V.D.S., R.A.R., I.Z.D., T.A.S., and R.M.G.; supervision, T.A.S. and R.M.G.; funding acquisition, R.M.G. All authors have read and agreed to the published version of the manuscript.

Funding: This research was funded by Coordenação de Aperfeiçoamento de Pessoal de Nível Superior-Brazil (CAPES)-Finance Code 001.

Conflicts of Interest: The authors declare no conflict of interest.

\section{References}

1. Gunn, R. Duplex Stainless Steels Microstructure Properties and Applications; Abington Publishing: Cambridge, UK, 2003.

2. Chaves, R.; Costa, I.; de Melo, H.G.; Wolynec, S. Evaluation of selective corrosion in UNS S31803 duplex stainless steel with electrochemical impedance spectroscopy. Electrochim. Acta 2006, 51, 1842-1846. [CrossRef]

3. Karlsson, L. Welding Duplex Stainless Steels-A Review Of Current Recommendations. Weld. World 2012, 56, 65-76. [CrossRef]

4. Lo, K.H.; Shek, C.H.; Lai, J.K.L. Recent developments in stainless steels. Mater. Sci. Eng. R Rep. 2009, 65, 39-104. [CrossRef]

5. Escobar, J.D.; Poplawsky, J.D.; Faria, G.A.; Rodriguez, J.; Oliveira, J.P.; Salvador, C.A.F.; Mei, P.R.; Babu, S.S.; Ramirez, A.J. Compositional analysis on the reverted austenite and tempered martensite in a Ti-stabilized supermartensitic stainless steel: Segregation, partitioning and carbide precipitation. Mater. Des. 2018, 140, 95-105. [CrossRef]

6. Escobar, J.D.; Oliveira, J.P.; Salvador, C.A.F.; Faria, G.A.; Poplawsky, J.D.; Rodriguez, J.; Mei, P.R.; Babu, S.S.; Ramirez, A.J. Meta-equilibrium transition microstructure for maximum austenite stability and minimum hardness in a Ti-stabilized supermartensitic stainless steel. Mater. Des. 2018, 156, 609-621. [CrossRef]

7. Pohl, M.; Storz, O.; Glogowski, T. Effect of Sigma-Phase Morphology on the Properties of Duplex Stainless Steels. Microsc. Microanal. 2005, 11, 230-231. [CrossRef]

8. Practical Guidelines for the Fabrication of Duplex Stainless Steels, 3rd ed.; IMOA (International Molybdenum Association): London, UK, 2014; ISBN 9781907470097. 
9. Pareige, C.; Novy, S.; Saillet, S.; Pareige, P. Study of phase transformation and mechanical properties evolution of duplex stainless steels after long term thermal ageing ( $>20$ years). J. Nucl. Mater. 2011, 411, 90-96. [CrossRef]

10. Calliari, I.; Pellizzari, M.; Zanellato, M.; Ramous, E. The phase stability in Cr-Ni and Cr-Mn duplex stainless steels. J. Mater. Sci. 2011, 46, 6916-6924. [CrossRef]

11. Børvik, T.; Lange, H.; Marken, L.A.; Langseth, M.; Hopperstad, O.S.; Aursand, M.; Rørvik, G. Pipe fittings in duplex stainless steel with deviation in quality caused by sigma phase precipitation. Mater. Sci. Eng. A 2010, 527, 6945-6955. [CrossRef]

12. Ibrahim, O.H.; Ibrahim, I.S.; Khalifa, T.A.F. Effect of aging on the toughness of austenitic and duplex stainless steel weldments. J. Mater. Sci. Technol. 2010, 26, 810-816. [CrossRef]

13. Lo, K.H.; Kwok, C.T.; Chan, W.K.; Zeng, D. Corrosion resistance of duplex stainless steel subjected to long-term annealing in the spinodal decomposition temperature range. Corros. Sci. 2012, 55, 267-271. [CrossRef]

14. Escriba, D.M.; Materna-Morris, E.; Plaut, R.L.; Padilha, A.F. Chi-phase precipitation in a duplex stainless steel. Mater. Charact. 2009, 60, 1214-1219. [CrossRef]

15. Magnabosco, R. Kinetics of sigma phase formation in a duplex stainless steel. Mater. Res. 2009, 12, 321-327. [CrossRef]

16. Dos Santos, D.C.; Magnabosco, R.; De Moura-Neto, C. Influence of sigma phase formation on pitting corrosion of an aged uns s31803 duplex stainless steel. Corrosion 2013, 69, 900-911. [CrossRef]

17. Ferro, P.; Bonollo, F. A Semiempirical Model for Sigma-Phase Precipitation in Duplex and Superduplex Stainless Steels. Metall. Mater. Trans. A 2012, 43, 1109-1116. [CrossRef]

18. dos Santos, D.C.; Magnabosco, R. Kinetic Study to Predict Sigma Phase Formation in Duplex Stainless Steels. Metall. Mater. Trans. A Phys. Metall. Mater. Sci. 2016, 47, 1554-1565. [CrossRef]

19. Långberg, M.; Zhang, F.; Grånäs, E.; Örnek, C.; Cheng, J.; Liu, M.; Wiemann, C.; Gloskovskii, A.; Keller, T.F.; Schlueter, C.; et al. Lateral variation of the native passive film on super duplex stainless steel resolved by synchrotron hard X-ray photoelectron emission microscopy. Corros. Sci. 2020, 174, 108841. [CrossRef]

20. Maurice, V.; Marcus, P. Progress in corrosion science at atomic and nanometric scales. Prog. Mater. Sci. 2018, 95, 132-171. [CrossRef]

21. Yongqiang, W.; Hao, S.; Na, L.; Yanhao, X.; Hemin, J. Effect of sigma phase precipitation on the pitting corrosion mechanism of duplex stainless steels. Int. J. Electrochem. Sci. 2018, 13, 9868-9887. [CrossRef]

22. Sieurin, H.; Sandström, R. Sigma phase precipitation in duplex stainless steel 2205. Mater. Sci. Eng. A 2007, 444, 271-276. [CrossRef]

23. Llorca-Isern, N.; López-Luque, H.; López-Jiménez, I.; Biezma, M.V. Identification of sigma and chi phases in duplex stainless steels. Mater. Charact. 2016, 112, 20-29. [CrossRef]

24. Pohl, M.; Storz, O.; Glogowski, T. Effect of intermetallic precipitations on the properties of duplex stainless steel. Mater. Charact. 2007, 58, 65-71. [CrossRef]

25. Zhang, L.; Zhang, W.; Jiang, Y.; Deng, B.; Sun, D.; Li, J. Influence of annealing treatment on the corrosion resistance of lean duplex stainless steel 2101. Electrochim. Acta 2009, 54, 5387-5392. [CrossRef]

26. Kumar, S.; Krisam, S.; Jacob, A.; Kiraly, F.; Keplinger, A.; Abart, R.; Povoden-Karadeniz, E. Microstructures and element distributions in an aged hyper duplex stainless steel and corresponding hardness variation. Mater. Des. 2020, 194, 108951. [CrossRef]

27. Gennari, C.; Pezzato, L.; Piva, E.; Gobbo, R.; Calliari, I. Influence of small amount and different morphology of secondary phases on impact toughness of UNS S32205 Duplex Stainless Steel. Mater. Sci. Eng. A 2018, 729, 149-156. [CrossRef]

28. Biezmaa, M.V.; Berlangab, C.; Argandonac, G. Relationship between Microstructure and Fracture Types in a UNS S32205 Duplex Stainless Steel. Mater. Res. 2013, 16, 965-969. [CrossRef]

29. Silva, D.D.S.; Sobrinho, J.M.B.; Souto, C.R.; Gomes, R.M. Application of electromechanical impedance technique in the monitoring of sigma phase embrittlement in duplex stainless steel. Mater. Sci. Eng. A 2020, 139457. [CrossRef] 
30. Silva, D.D.S.; Raimundo, R.A.; Torquato, R.A.; Faria, G.L.; Morales, M.A.; Simões, T.A.; Gomes, R.M. Low-Field Magnetic Analysis for Sigma Phase Embrittlement Monitoring in Thermally Aged 22Cr Duplex Stainless Steel. J. Magn. Magn. Mater. 2020, 167072. [CrossRef]

31. Haghdadi, N.; Laleh, M.; Kosari, A.; Moayed, M.H.; Cizek, P.; Hodgson, P.D.; Beladi, H. The effect of phase transformation route on the intergranular corrosion susceptibility of 2205 duplex stainless steel. Mater. Lett. 2019, 238, 26-30. [CrossRef]

32. Zanotto, F.; Grassi, V.; Balbo, A.; Monticelli, C.; Melandri, C.; Zucchi, F. Effect of brief thermal aging on stress corrosion cracking susceptibility of LDSS 2101 in the presence of chloride and thiosulphate ions. Corros. Sci. 2018, 130, 22-30. [CrossRef]

33. Zhang, Z.; Jing, H.; Xu, L.; Han, Y.; Zhao, L.; Lv, X. Effect of post-weld heat treatment on microstructure evolution and pitting corrosion resistance of electron beam-welded duplex stainless steel. Corros. Sci. 2018, 141, 30-45. [CrossRef]

34. ASTM A 240/A 240M-20: Standard Specification for Chromium and Chromium-Nickel Stainless Steel Plate, Sheet, and Strip for Pressure Vessels and for General Applications; ASTM International: West Conshohocken, PA, USA, 2020.

35. ASTM A923-14: Standard Test Methods for Detecting Detrimental Intermetallic Phase in Duplex Austenitic/Ferritic Stainless Steels; ASTM International: West Conshohocken, PA, USA, 2014.

36. ASTM A370-20: Standard Test Methods and Definitions for Mechanical Testing of Steel Products; ASTM International: West Conshohocken, PA, USA, 2020.

37. Örnek, C.; Engelberg, D.L. Correlative EBSD and SKPFM characterisation of microstructure development to assist determination of corrosion propensity in grade 2205 duplex stainless steel. J. Mater. Sci. 2016, 51, 1931-1948. [CrossRef]

38. Warren, A.D.; Harniman, R.L.; Guo, Z.; Younes, C.M.; Flewitt, P.E.J.; Scott, T.B. Quantification of sigma-phase evolution in thermally aged 2205 duplex stainless steel. J. Mater. Sci. 2016, 51, 694-707. [CrossRef]

39. Michalska, J.; Sozańska, M. Qualitative and quantitative analysis of $\sigma$ and $\chi$ phases in 2205 duplex stainless steel. Mater. Charact. 2006, 56, 355-362. [CrossRef]

40. Breda, M.; Calliari, I.; Ramous, E.; Pizzo, M.; Corain, L.; Straffelini, G. Ductile-to-brittle transition in a Zeron®100 SDSS in wrought and aged conditions. Mater. Sci. Eng. A 2013, 585, 57-65. [CrossRef]

41. Hong, T.; Nagumo, M. Effect of surface roughness on early stages of pitting corrosion of Type 301 stainless steel. Corros. Sci. 1997, 39, 1665-1672. [CrossRef]

42. Abosrra, L.; Ashour, A.F.; Mitchell, S.C.; Youseffi, M. Corrosion of Mild Steel and 316L Austenitic Stainless Steel with Different Surface Roughness in Sodium Chloride Saline Solutions. WIT Trans. Eng. Sci. 2009, 65, 161-172. [CrossRef]

43. Ebrahimi, N.; Momeni, M.; Kosari, A.; Zakeri, M.; Moayed, M.H. A comparative study of critical pitting temperature (CPT) of stainless steels by electrochemical impedance spectroscopy (EIS), potentiodynamic and potentiostatic techniques. Corros. Sci. 2012, 59, 96-102. [CrossRef]

44. Macdonald, J.R. Impedance Spectroscopy: Emphasizing Solid Materials and Systems; Wiley: New York, NY, USA, 1987; ISBN 0471831220.

45. Brug, G.J.; van den Eeden, A.L.G.; Sluyters-Rehbach, M.; Sluyters, J.H. The analysis of electrode impedances complicated by the presence of a constant phase element. J. Electroanal. Chem. Interfacial Electrochem. 1984, 176, 275-295. [CrossRef]

46. Zheng, X.; Zhang, S.; Li, W.; Yin, L.; He, J.; Wu, J. Investigation of 1-butyl-3-methyl-1H-benzimidazolium iodide as inhibitor for mild steel in sulfuric acid solution. Corros. Sci. 2014, 80, 383-392. [CrossRef]

47. Frankel, G.S. Pitting Corrosion of Metals. J. Electrochem. Soc. 1998, 145, 2186. [CrossRef]

48. Ayati, N.S.; Khandandel, S.; Momeni, M.; Moayed, M.H.; Davoodi, A.; Rahimizadeh, M. Inhibitive effect of synthesized 2-(3-pyridyl)-3,4-dihydro-4-quinazolinone as a corrosion inhibitor for mild steel in hydrochloric acid. Mater. Chem. Phys. 2011, 126, 873-879. [CrossRef]

49. He, L.; Wirian, L.; Singh, P.M. Effects of Isothermal Aging on the Microstructure Evolution and Pitting Corrosion Resistance of Lean Duplex Stainless Steel UNS S32003. Metall. Mater. Trans. A Phys. Metall. Mater. Sci. 2019. [CrossRef]

50. Zeng, H.; Yang, Y.; Xu, R.; Xin, S.; Li, M. Pitting corrosion resistance of sensitized type 2205 duplex stainless steel in hot concentrated seawater. J. Solid State Electrochem. 2019, 23, 2793-2801. [CrossRef] 
51. Silva, D.D.S.; Simões, T.A.; Macedo, D.A.; Bueno, A.H.S.; Torres, S.M.; Gomes, R.M. Microstructural influence of sigma phase on pitting corrosion behavior of duplex stainless steel/ $\mathrm{NaCl}$ electrolyte couple. Mater. Chem. Phys. 2020, 124056. [CrossRef]

52. Ramirez, A.J.; Lippold, J.C.; Brandi, S.D. The relationship between chromium nitride and secondary austenite precipitation in duplex stainless steels. Metall. Mater. Trans. A Phys. Metall. Mater. Sci. 2003, 34, 1575-1597. [CrossRef]

Publisher's Note: MDPI stays neutral with regard to jurisdictional claims in published maps and institutional affiliations.

(C) 2020 by the authors. Licensee MDPI, Basel, Switzerland. This article is an open access article distributed under the terms and conditions of the Creative Commons Attribution (CC BY) license (http://creativecommons.org/licenses/by/4.0/). 